\title{
Parasitic burden in high altitude wild ruminants: Himalayan Tahr (Hemitragus jemlahicus Smith, 1826) and Barking Deer (Muntiacus vaginalis Boddaert, 1785) of Rara National Park, Nepal
}

\author{
Chanda Thapa and Mahendra Maharjan* \\ Central Department of Zoology, Tribhuvan University, Kirtipur, Kathmandu, Nepal.
}

\begin{abstract}
Parasites of two high altitude ruminants Himalayan Tahr (Near Threatened) and Barking Deer (Vulnerable) were examined from the Rara National Park, located at $3000-4000 \mathrm{~m}$ altitude of Nepal, for the first time. A total of 51 faecal samples, 17 from Himalayan Tahr and 34 from Barking Deer were collected in the month of May/June 2012 and 2013. Parasites were found in all the samples of Himalayan Tahr and 33 samples (97.06\%) of Barking Deer. Coccidian oocysts ( Eimeria sp.), eggs of cestodes (Moniezia sp.) and gastrointestinal nematodes (Strongyloides sp., Trichuris sp., Oxyuris $s p$., Ascaris sp., Trichostrongylus sp. and Haemonchus sp.) and bronchopulmonary nematode larvae (Dictyocaulus sp. and Muellerius sp.) were identified by means of coprological techniques. Himalayan Tahrs were found to be highly infected with Eimeria sp. (88.24\%) and Moniezia sp. (70.59\%) compared to Barking Deers, Eimeria sp. (73.53\%) and Moniezia sp. (47.06\%). In Himalayan Tahr, prevalence of Oxyuris was found to be highest $(88.24 \%)$ among various nematode parasites followed by Stongyloides sp. (64.71\%), Ascaris sp. (52.94\%), Trichostrongylus sp. (11.76\%), Dictyocaulus sp. $(11.76 \%)$, Muellerius sp. (11.76\%) and Haemonchus sp. (5.88\%) while in Barking Deer, 26 (76.47\%) samples were found to be positive for nematode parasites. Among the nematode eggs examined, Oxyuris revealed highest prevalence $(70.59 \%)$ followed by Ascaris sp. (17.65\%), Trichuris $s p .(8.82 \%)$, Dictyocaulus sp. (8.82\%) and Haemonchus sp. (2.94\%). Present findings highlight that the parasitic diseases are posing considerable threat in the conservation of wild life in Nepal.
\end{abstract}

Key words: Helminthes, Mammals, Eimeria, Rara National Park

\section{Introduction}

Himalayan Tahr (Hemitragus jemlabicus) is a relative of the wild goat having massive horns. In female Tahr, horns are smaller and manes wanted (Shrestha, 1997). They are distributed from temperate to sub-alpine zones and steep rocky mountain sides between elevations of 3,000 $\mathrm{m}$ and 4,000 $\mathrm{m}$ in China (Souther $\mathrm{n}$ Tibet), India and Nepal. They are assessed as Near Threatened globally and nationally (Jnawali et al., 2011). In Nepal they are distributed in lower parts of $\mathrm{K}$ aski, Manang and Annapur na Conservation Area (Mustang), Kanchanjanga Conservation Area, Langtang National Park, Makalu Barun National Park, Western part of Gorkha within the Manaslu conser vation area, Sagar matha National Park, Rara National Park, Khaptad National Park and district of Dolakha and Sindhupalchowk in the total number more than 2,000 (Jnawali et al., 2011).

The Barking Deer occurs in dense tropical and subtropical forests along with thickly wooded hills of Bangladesh, Bhutan, Cambodia,

${ }^{*}$ Corresponding author, email address: maharjan.m@gmail.com
China, Hong Kong, India, Myanmar, Pakistan, Sri Lanka, Thailand, Vietnam and Nepal (Jnawali et al., 2011). According to Shrestha (1997), Barking Deer are widespread in oak and lower conifer forest up to $3500 \mathrm{~m}$ elevations in Nepal. The species prefer gently sloping terrain and also occurs in the steeper hills. This species is widely distributed across Nepal within all protected areas. Globally the Barking Deer is categorized in Least Concern but in Nepal it has been assessed as Vulnerable (Jnawali et al., 2011).

Parasitic diseases cause severe morbidity and mortality in animals. Coccidiosis is a serious disease caused by coccidian protozoan parasites in small ruminants as well as large ruminants causing severe damage of the host's intestinal epithelial cells, making them more susceptible to bacterial invasion and allowing fatal diarhoea. They especially include Fasciola sp., Dicrocoelium sp., Schistosome sp. and Paramphistome species. Cestodes found in gut and acquired by ingesting contaminated food or water found to be 
largely affecting the $\mathrm{r}$ uminants and comprise the genus Moniezia. Moniezia sp. in wild and domesticated ruminants causes infections by ingesting herbage contaminated with the mites carrying the infective stage of the parasite. Heavy infection cause poor growth and diarrhoea in lambs. Moniezia sp. requires two hosts viz. definitive host (sheep, goat, cattle and some ruminants) and intermediate host (orbatid mites) to complete its life cycle. The mostly prevalent nematodes in wild ruminates are Strongyloides sp., Oxyuris sp., Trichostrongylus sp., Haemonchus sp., Ascaris sp., Dictyocaulus sp., Muellerius sp., Trichuris sp. etc. These nematodes in the small intestine may cause severe damage to the intestinal mucous membrane with similar effects. F emale roundworms lay microscopic eggs that pass in the manure of the infected animals. Within a few days the lar va hatches from the egg. The larva passes via second and third stage. During the course they infect the pasture. Himalayan T ahr and Barking Deer get infected when they graze onto contaminated pasture. The lar va mature in the intestine, mate and begins laying eggs. Adult roundworms can cause anemia, diarrhea, poor growth and even death. Hookworm causes anaemia, laziness and lack of physical and mental ability. Heavy infection may cause severe loss of blood.

\section{Materials and methods}

Rara National Park is located in the North-Western high mountains of Nepal. The park was established in 1976 with the objectives of conserving biodiversity and maintaining the unique landscape. Its area of $106 \mathrm{sq} . \mathrm{km}$. makes it the smallest of all protected areas of Nepal and is highlighted by $10.8 \mathrm{sq} . \mathrm{km} \mathrm{R}$ ara Lake. The lake is largest in Nepal and the park is named af ter it. Faunal diversity includes about 51 species of mammals, 272 bird species and snow trout. The park is an ideal habitat for the endangered Musk Deer (Moschus chrysogaster), Himalayan Tahr (Hemitragus jemlabicus), Himalayan Black Bear (Ursus selwnarctos thibetanus), Himalayan Ghoral (Nemorhaedus goral), Jackal (Canis aureus), YellowThroated Marten (Martes flavigula), Wild Dog (Cuon alpines), wild boar (Sus scrofa), common Langur (Presbytis entellus), Rhesus Macaque (Macaca mulatta) and Common Otter (Lutra lutra) (DNPWC, 2012).

The present study was designed to assess the intestinal parasitic infection in Himalayan Tahr and Barking Deer of R ara National Park by collecting fresh faecal pellets using line transect method. The collected stool samples were freshly preser ved in sterilized vials containing $2.5 \%$ potassium dichromate solution. A total of 17 faecal samples of Himalayan Tahr were collected from the EastWest slope of mountain sur rounding the Rara Lake during the month of May/June 2012 and 34 faecal samples of Barking Deer were collected from same site during the month of May/June 2013. East-West facing slope of the mountain which was considered as the major habitat of Himalayan Tahr and North-East facing slope of mountain sur rounding the Rara lake was chosen to collect faeces samples of Barking Deer. These two Rara lake surrounding mountains had been divided into 12 and 18 transects each.
Microscopic examination of the faecal samples was carried out in parasitological laboratory, Central Department of Zoology, Tribhuvan University. The faecal samples were subjected to coprological examination by differential floatation and sedimentation technique. Necessary size of the eggs and oocysts were measured by using ocular and stage micrometer with microphotography. Identification of the parasitic eggs and oocysts were done on the basis of the shape and size as described earlier (Farooq et al., 2012; Gupta et al., 2011; Saseendran et al., 2003).

\section{Results and discussion}

Out of 34 fresh faecal samples of Barking Deer examined, 33 samples (97.06\%) were found positive for parasitic infections having protozoan infections (Plate 1: Photos 1-3) in 25 samples (73.53\%), cestode infections (Plate 2: Photo 1) in 16 samples (47.06\%) and nematode infections (Plate 2: Photos 2-7) in 26 samples (76.47\%) whereas in Himalayan Tahr, out of 17 samples examined 15 samples (88.24\%) were found positive including protozoan parasitic oocysts in 15 samples (88.24\%), cestode eggs in 12 samples (70.59\%) and nematodes in all the samples (100\%).

Altogether 10 parasitic genera were observed in the present study. One genus each of protozoa (Eimeria) and cestoda (Moniezia) were observed in both $\mathrm{r}$ uminants but eight and five nematode genera were found in Himalayan Tahr and Barking Deer respectively. In Himalayan Tahr, Eimeria and Moniezia infections were observed in $88.24 \%$ and $70.59 \%$ samples respectively. Where as in Barking Deer, $73.53 \%$ and $47.06 \%$ samples were found positive forEimeria and Moniezia infections respectively. In Himalayan Tahr, prevalence of Oxyuris was found to be highest (88.24\%) among various nematode parasites followed by Stongyloides sp. (Plate 3: Photo 1) $64.71 \%$, Ascaris $52.94 \%$, Trichostrongylus sp. $11.76 \%$, Dictyocaulus sp. (Plate 3: Photo 3) 11.76\%, Muellerius sp. (Plate 3: Photo 2) $11.76 \%$ and Haemonchus sp. $5.88 \%$ while in Barking Deer, out of 34 samples, 26 (76.47\%) samples were found to be positive for nematode parasites. Among the nematodes, Oxyuris sp. revealed highest prevalence (70.59\%) followed by Ascaris sp. 17.65\%, Trichuris sp. 8.82\%, Dictyocaulus sp. $8.82 \%$ and Haemonchus sp. 2.94\% (Table 1).

In the present study, the rate of mixed infection was also observed. All 17 positive samples of Himalayan T ahr were found to have mixed infections with 3-6 genera in each sample. Among the 17 samples examined, four (23.53\%) samples were found with triple infection and thirteen (76.47\%) samples with multiple infections. None of the sample was found with single and double infection in Himalayan Tahr. Out of 34 samples examined, eight (23.53\%) samples with single infection, 10 (29.41\%) samples with double infection, seven (20.59\%) samples with triple infection and eight (23.53\%) samples with multiple infections were observed in Barking Deer.

\section{通TU-CDES}


Table 1 Prevalence of intestinal parasites in Himalayan Tahr and Barking Deer

\begin{tabular}{|c|c|c|c|c|c|c|}
\hline S. $\mathbf{N}$. & Class & Identified intestinal paresites & Prevalence in Himalayan Tahr & Prevalence in Barking Deer & $\chi^{2}$-Value & $p$-Value \\
\hline 1. & Sporozoa & Eimeria & $15(88.24 \%)$ & $25(73.53 \%)$ & 1.449 & 0.229 \\
\hline 2. & Cestoda & Moniezia & $12(70.59 \%)$ & $16(47.06 \%)$ & 2.534 & 0.111 \\
\hline 3. & Nematoda & Oxyuris & $15(88.24 \%)$ & $24(70.59 \%)$ & 1.962 & 0.161 \\
\hline 4. & & Ascaris & $9(52.94 \%)$ & $5(17.65 \%)$ & 8.319 & 0.004 \\
\hline 5. & & Trichuris & $2(11.76 \%)$ & $3(8.82 \%)$ & 0.111 & 0.739 \\
\hline 6. & & Dictyocaulus & $2(11.76 \%)$ & $3(8.82 \%)$ & 0.111 & 0.739 \\
\hline 7. & & Haemonchus & $1(5.88 \%)$ & $1(2.94 \%)$ & 0.260 & 0.610 \\
\hline 8. & & Strongyloides & $11(64.71 \%)$ & & 28.050 & 0.000 \\
\hline 9. & & Trichostrongylus & $2(11.76 \%)$ & & 4.163 & 0.041 \\
\hline 10. & & Muellerius & $2(11.76 \%)$ & & 4.163 & 0.041 \\
\hline
\end{tabular}

Intensity of parasitic infection has been assessed based upon the number of eggs/oocyst and larvae found per microscopic field. Intensity of light infection of Eimeria sp. was found in 7 (41.18\%) samples, 5 (29.41\%) samples with mild infection and 3 (17.65\%) positive samples with moderate infection. Among helminthes, the high intensity of light infection was noted due to Oxyuris sp. with 8 (47.06\%) samples and mild infection was due to Strongyloides sp. with 6 (35.29\%) samples while high intensity of moderate infection was due to Oxyuris sp. with 2 (11.76\%) samples but the heavy infection was noted due to the only Oxyuris sp. in one (5.88\%) sample (Table no. 2).

Table 2 Intensity of infection of intestinal parasites in Himalayan Tahr

\begin{tabular}{lllcccc}
\hline S. N. & Class & Name of genera & + & ++ & +++ & ++++ \\
\hline 1. & Sporozoa & Eimeria & 7 & 5 & 3 & - \\
2. & Cestode & Moniezia & 7 & 3 & 2 & - \\
3. & Nematode & Oxyuris & 8 & 4 & 2 & 1 \\
4. & & Ascaris & 7 & 2 & - & - \\
5. & & Trichuris & 2 & - & - & - \\
6. & & Dictyocaulus & 2 & - & - & - \\
7. & & Haemonchus & 1 & - & - & - \\
8. & & Stongyloides & 5 & 6 & - & - \\
9. & & Trichostrongylus & 2 & - & - & - \\
10. & & Muellerius & 2 & - & - & - \\
\hline
\end{tabular}

Intensity of light infection of Eimeria sp. was found in 8 (23.53\%) samples, mild infection in 16 (47.06\%) samples and moderate infection in only one (2.94\%) sample but multiple infections were not observed due to Eimeria sp. Among helminths, high intensity of light infection, mild infection, moderate infection and heavy infection was noted due to Oxyuris sp. with 9 (26.47\%) samples, 10 (29.41\%) samples, 2(5.88\%) samples and 3 (8.82\%) samples respectively (Table 3 ).

It is well known that parasites are cosmopolitan in distribution and all animals, whether humans, domestic animals and wild animals bear different kinds of parasites. Many studies have been carried out regarding the intestinal parasites of human because we are always eager to know about our health. Veterinarians are always interested to research about domestic animals, whereas
Table 3 Intensity of infection of intestinal parasites in Barking Deer

\begin{tabular}{lllcccc}
\hline S. N. & Class & Name of genera & + & ++ & +++ & ++++ \\
\hline 1. & Sporozoa & Eimeria & 8 & 16 & 1 & - \\
2. & Cestode & Moniezia & 4 & 8 & 2 & 2 \\
3. & Nematode & Oxyuris & 9 & 10 & 2 & 3 \\
4. & & Ascaris & 4 & 1 & - & - \\
5. & & Trichuris & 3 & - & - & - \\
6. & & Dictyocaulus & 3 & - & - & - \\
7. & & Haemonchus & 1 & - & - & - \\
\hline
\end{tabular}

Note:

$+\quad=$ less than 2 ova per field. $\}$ Light infection

$++\quad=2-4$ ova per field. $\}$ Mild infection

$+++\quad=4-6$ ova per field. $\}$ Moderate infection

$++++=6$ or more ova per field.\} Heavy infection

very little attention is paid to the wild animals. In the present study, the study of gastrointestinal parasites of Hemitragus jemlabicus (Himalayan Tahr) and Muntiacus vaginalis (Barking Deer) has been carried out for the first time in Nepal. The research so far has not been adequate enough, especially in context of Nepal. Present study explored parasitic burden, multiple infection and intensity in two high altitude wild ruminant species, Himalayan Tahr and Barking Deer in Rara National Park.

The parasites identified in both Himalayan Tahr and Barking Deer were almost same, since we observed oocysts of Eimeria sp., eggs of Moniezia sp. and larvae and eggs of gastrointestinal nematodes. These results are in agreement with those reported in wild ruminants of different countries including Nepal (Varadharajan et al., 1999, Vezquez et al., 2010, Gupta et al., 2011, Farooq et al., 2012 and Ban 2012). In present study , 10 genera of intestinal parasite in Himalayan Tahr and seven genera of intestinal parasite in Barking Deer has been reported but trematode eggs were not observed in both ruminants which agree with the results of previous studies in free ranging Roe Deer in Spain (V azquez et al., 2009) however Fasciola were observed in wild ruminants (Varadharajan et al., 1999, Karki \& Manandhar, 2008, Gupta et al., 2011, Farooq et al., 2012 \& Ban, 2012). 

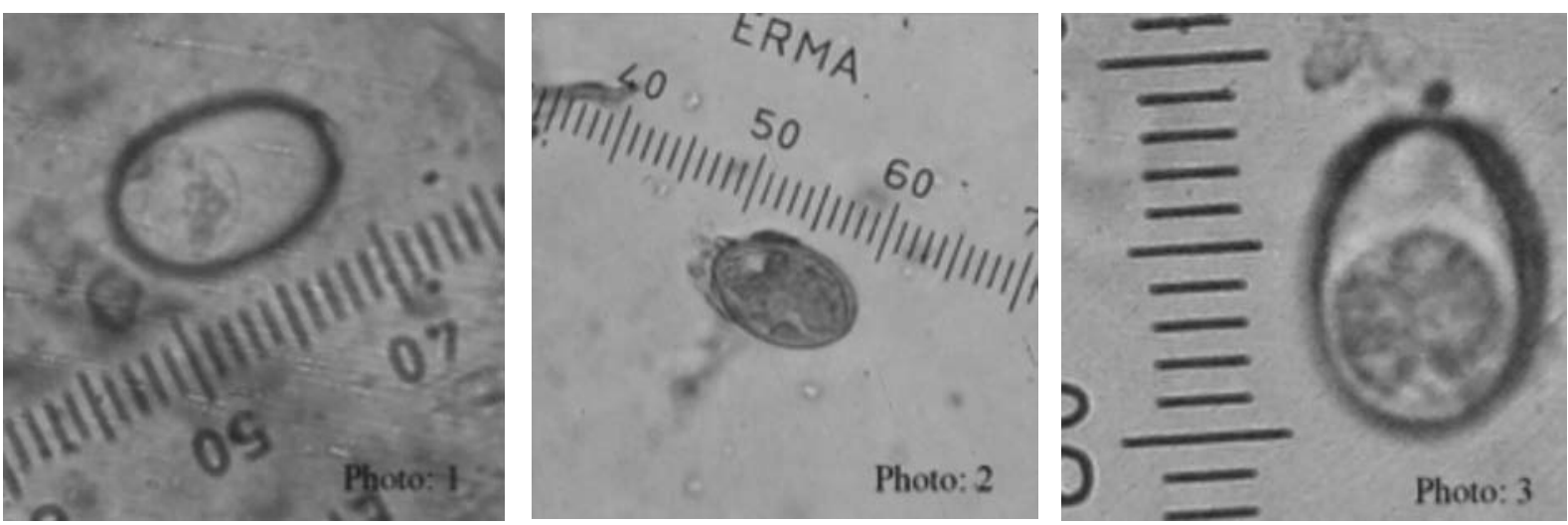

Plate 1 Ocyst of Eimeria sp. 1) Eimeria with micropyle (33 $\mu \mathrm{m}), 2)$ Eimeria without micropyle ( $24 \mu \mathrm{m})$ and 3) Sporulated Oocyst of Eimeria $(24 \mu \mathrm{m})$
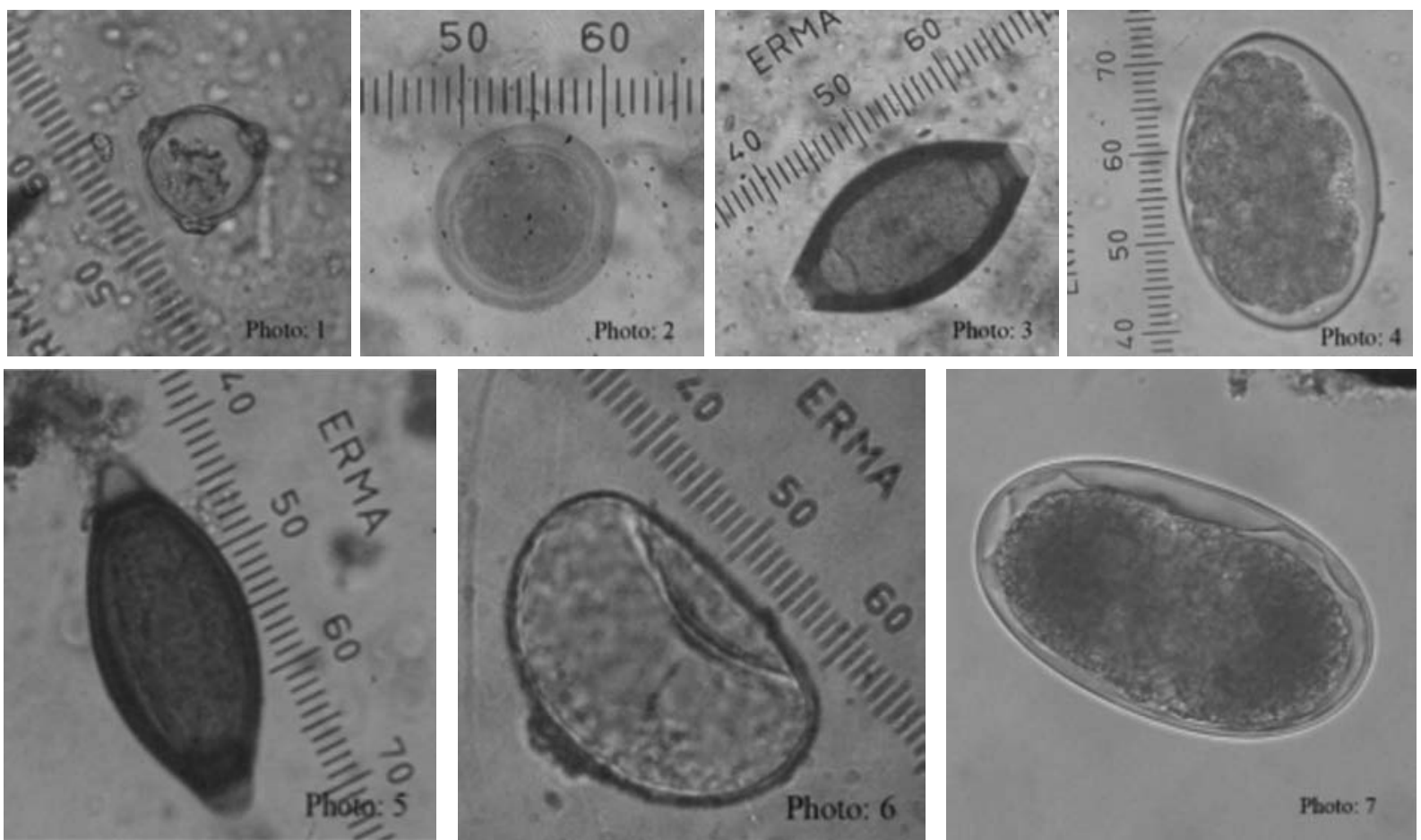

Plate 2 Eggs of cestode and nematode parasites: 1. Moniezia sp. (30 $\mu \mathrm{m}), 2$. Ascaris sp. (39 $\mu \mathrm{m}), 3$. Trichuris sp. 4. Trichostrongylus sp. $(96 \mu \mathrm{m}) 5$. Trichuris sp. $(81 \mu \mathrm{m})$, 6. Oxyuris sp. $(72 \mu \mathrm{m})$ and 7. Haemonchus sp.
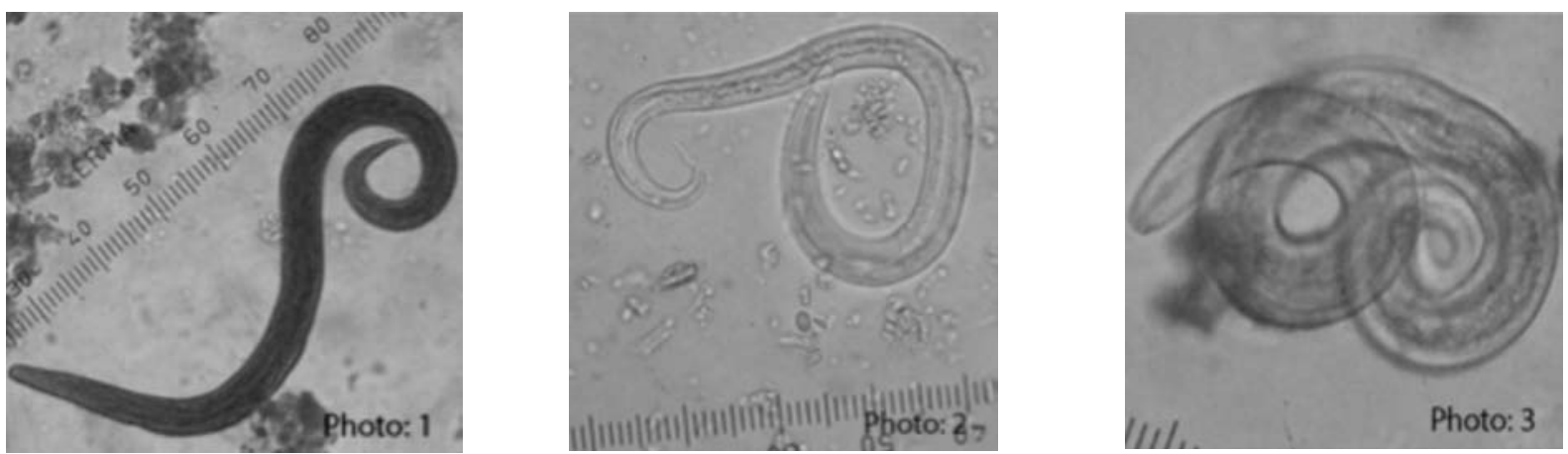

Plate 3 Larva of nematode parasites 1). Strongyloides larva, 2). Muellerius larva and Photo: 3). Dictyocaulus larva

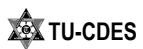


In general the high prevalence of parasitic infection were observed having direct life cycle as coccidian and gastrointestinal nematodes except parasite having indirect life cycle as Moniezia sp. but trematodes weren't observed in both ruminants. These results agreed with those from a previous study in roe deer (Vazquez et al., 2009) and could be related with the difficulty of finding the intermediate hosts. The prevalence of gastrointestinal parasites among wild animals in V.O.C. Park and mini zoo, Kerala, India (Varadharajan et al, 2000) showed helminthes (58\%) and protozoan parasites (6\%) in captive animals. Comparing to the present study the helminth parasitic burden in Himalayan Tahr (100\%) and in Barking Deer (82.35\%) and protozoan parasites in Himalayan Tahr (88.24\%) and Barking Deer (73.53\%) has been found more higher whereas prevalence of helminth parasite (74\%) and protozoan infection (23\%) in wild mammals in the zoological garden, Kerala, India (Varadharajan et al., 1999) was lower compared to the present study. Regarding coccidian parasitic burden in both Himalayan Tahr (88.24\%) and Barking Deer (73.53\%) in this study was similar to that reported by T ovassoli et al., (2010) in wild sheep in Iran (80.48\%) but higher than in roe deer from Galacia, NW Spain (38\%) (Diaz et al., 2010).

Vetyska (1980) found four coccidian species and 13 helminth species in Roe Deer. It showed higher number of helminth species infecting roe deer compared to the present study ( 8 and 5 helminth species in Himalayan Tahr and Barking Deer respectively). To identify the genus Eimeria up to the species level spor ulation experiment by culture is a must which was not done in present study. Both Himalayan Tahr and Barking Deer were found to be infected with large number of Eimeria species. On the basis of structure (with micropyle and without micropyle), shape (sporulated and unsporulated) and size ranging from $15 \mu \mathrm{m}$ to $54 \mu \mathrm{m}$. It is assumed that both of these two $\mathrm{r}$ uminant species were found to be infected with more than six Eimeria species which showed close similarity to the result of Diaz et al. (2010) showing seven species of Eimeria in Roe Deer, but showed lower number of Eimeria infection in wild sheep (Tovassoli et al., 2010). Moniezia sp. a cestode parasitic infection has been reported from Pakistan in wild and domestic ruminants (Farooq et al., 2012) as reported in the present study. Moniezia sp. (3.0\%) observed in Roe Deer from NW Spain (V azquez et al., 2009) and Moniezia (5.0\%) reported among captive elephant in Nepal (K arki and Manandhar, 2008) were much lower as compared to the present study $70.59 \%$ and $47.06 \%$ in Himalayan Tahr and Barking Deer respectively). It may conclude that these two $r$ uminants are harboring large number of infected mites (inter mediate host). Multiple parasitic infections were found to be more common in both Himalayan Tahr and Barking Deer. Multiple infections in Himalayan Tahr was found to be higher (76.47\%) than in Barking Deer (23.53\%). It was observed that most of them were infected with Oxyuris, Eimeria and Moniezia. Four (23.53\%) faecal samples showed combination of three species in Himalayan Tahr but in Barking Deer it was found to be slightly less (seven faecal samples,
20.59\%). Single infection was observed in eight (23.53\%) faecal samples where double infection in 10 samples (29.41\%) in Barking Deer. However, non of the samples were found to be infected with single and double infection in Himalayan Tahr. Mortality of animals are increased when animals harbour lar ge intensity of single parasitic infection.

\section{Conclusion}

Parasitic infection in both high altitude wild ruminants Himalayan Tahr (Near Threatened) and Barking Deer (Kulnerable) were found very high with $100 \%$ and $97.06 \%$ respectively. The ruminants were found to be infected with coccidian parasites (Eimeria sp.), Cestode parasite (Moniezia sp.) and gastrointestinal nematodes (Strongyloides, Trichuris, Oxyuris, Ascaris, Trichostrongylus and Haemonchus) and bronchopulmonar y nematode lar vae (Dictyocaulus sp. and Muellerius sp.).

\section{Acknowledgements}

The authors are thankful to the Department of National Park and Wildlife Conservation (DNPWC) for providing permission to carry out this study in Rara National Park. The authors express sincere acknowledgement to the warden of Rara National Park and game scout Mr. Bir Bahadur Buda for their support in identification of faecal samples. Authors are thankful to Mr. Hari Prasad Sharma, Recipient of Rufferd Small Grant for Red Panda Project in R ara National Park for providing the travel support.

\section{References}

Ban, S. (2012). Conservation status of Blackbuck (Antelope cervicapra Linneaus, 1758) at Khairapur, Bardia, Nepal. M.Sc. Thesis. Central Department of Zoology , Tribhuvan University, Kathmandu, Nepal.

Diaz, P., Painceira, A., Dacal, V., Vazquez, L., Cienfuegos, S., Arias, M.S. et al., (2010). Eimeria infection in wild ( Capreolus capreolus) and extensive reared domestic r uminants from Galacia (NW Spain). Revista Ibero-Latinoamericana de Parasitologia, 69(1), 83-89.

DNPWC (2012). Rara National Park (Booklet). Department of National Parks and Wildlife Conservation, Kathmandu, Nepal.

Farooq, Z., Mushtaq, S., Iqbal, Z. and Alchtar, A. (2012). Parasitic helminthes of domesticated and wild ruminants in Cholistan desert of Pakistan. International Journal of Agriculture and Biology, 14, 63-68.

Gupta, A., Dixit, A.K., Dixit, P., Mahajan, C. and Shrivastava, A.B. (2011). Incidence of gastrointestinal parasites in wild ruminants around Jabalpur, India. Journal of Threatened Taxa, 3(11), 2226-2228.

Jnawali, S.R., Baral, H.S., Lee, S., Acharya, K.P., Upadhyay, G.P., Pandey, M. et al. (2011) (compilers). The Status of the Nepal Mammals: The National Red List Series. Department of National Park and Wildlife Conservation (DNPWC) Kathmandu, Nepal 276 p. 
Karki, K. and Manandhar, P. (2008). Incidence of Gastrointestinal Helminthes in Captive Elephants of Wildlife Reserves of Nepal. Retrieved- 4 February, 2010 from http:/wwwarticlesbase.com/ health-articles/incidence-of-gatrointestinal-helminthes-incaptive-elephants-in-wildlife-reserves-of-nepal-335689. html.

Saseendran, P.C., Rajendran, S., Subramanian, H. and Anil, K.S. 2003. Incidence of gastrointestinal parasites in Nilgiri T ahr (Hemitragus hylocrius) of Eravikulam National Park, Kerala, India. Zoos' Print Journal, 18(3), 1057.

Shrestha, T.K. (1997). Mammals of Nepal (With reference to those of India, Bangladesh, Bhutan and Pakistan). K athmandua, Bimala Shrestha 371p.

Tovassoli, M. and Khoshvaghti, H. (2010). Helminthes and Coccidia Infection of Wild Sheep in Kabodan Island of National Park of Urmia Lake, Iran. Veterinary Research Forum, 1, 26-29.

Varadharajan, A. and Kandasamy, A. (2000). A survey of gastrointestinal parasites of wild animals in captivity in the V.O.C. Park and Mini Zoo, Coimbatore, India. Zoos' Print Journal, 15(5), 257-258.
Varadharajan, A. and Pythal, C. (1999). A preliminary investigation on the parasites of wild animals at the Zoological Garden, Thiruvananthapurum, Kerala, India. Zoos' Print Journal, 14 (3), 159-164.

Vazquez, L., Dacal, V., Pato, FJ., Paz-Silva, A., Diezbanos, N., Lopez, C. et al., (2009). The occurrence of endoparasites of roe deer (Capreolus capreolus) in two different areas from North-West Spain. Revista Ibero-Latinoamericana de Parasitologia, 68(1), 25-31.

Vazquez, L., Painceira, A., Dacal, V., Pato, FJ., Pandero, R., Lopez, C. et al., (2010). Long-term study of internal parasitic infections in free-ranging roe deer ( Capreolus capreolus) from NW Spain. Revista Ibero-Latinoamericana de Parasitologia, 69(2), 172-177.

Vetyska, V. (1980). Endoparasites of Roe Deer in the Strak onice Region. Acta Veterinaria Brno, 49, 91-103. 